\title{
El ensayo visual: repensando las comunicaciones desde la hibridez
}

\author{
Recibido: 31 de julio de 2018 \\ Aceptado: 4 de septiembre de 2018 \\ Publicado: 28 de noviembre de 2018
}

\author{
Orietta Marquina Vega \\ orietta.marquina@pucp.edu.pe \\ Gabriela Núñez Murillo \\ nunez.g@pucp.edu.pe \\ Valeri Hernani Valderrama \\ vhernani@pucp.pe
}

Pontificia Universidad Católica del Perú

\begin{abstract}
Resumen: Se reflexiona sobre el ensayo visual, como instrumento de investigación dentro de la comunicación social, que construye sentido a partir de la imagen. Desde la cultura visual, vincula ideas, emociones y afectos a favor de una esfera pública inclusiva al servicio del bien común. Su naturaleza híbrida (que entrelaza el lenguaje visual con el verbal) le permite no solo narrar sino argumentar un pensamiento que incluye la subjetividad del investigador, pero también la del Otro. Es desde esta relación con la Otredad que el ensayo visual propone un conocer y un interactuar diferente con la realidad, en respuesta a la estetización de la comunicación social. Así, el ensayo visual obtiene su veracidad desde la intersubjetividad con la que se construye. En este artículo se presentan los cambios en la comunicación actual a los que responde, sus principales características, y sus implicancias sobre las comunicaciones desde la academia, las aulas y el desempeño de la profesión.
\end{abstract}

Palabras clave: Ensayo visual, ensayo fotográfico, cultura visual, investigación desde la práctica, comunicación multisensorial, metodología híbrida, pensamiento visual, estética y comunicación.

Abstract: This article reflects on visual essay as a research instrument within social communication, which builds meaning from the visual, linking ideas, emotions and affects, and contributes to build an inclusive public sphere at the service of the public good, within visual culture. Its hybrid nature intertwines visual and verbal language, which, unlike other visual and audiovisual products, allows argumentation and to build a thought that includes subjectivity, but also to the Other. It is from this relationship with the Other that 
proposes a way of learning and interacting with reality as something different, according to sensitivities that aestheticization of social communication demands, and obtains its truth from the intersubjectivity with which it is constructed.

Key words: Visual Essay, Photo Essay, Visual Culture, Practice-Led research, Multisensorial Communication, Hybrid Research, Visual Thinking, Aesthetics and Communication.

\section{Introducción}

Al ingresar al siglo XXI, se introdujo una serie de cambios, sociales, económicos, culturales y tecnológicos que ha modificado sustantivamente la vida cotidiana de los individuos, las sociedades y la comunicación social. Expresiones como "la tercera ola" (Toffler, 1980) o "la tercera revolución industrial" o la "era del conocimiento" (Roel, 1998) dan una idea de la magnitud de dichos cambios. Sin embargo, muchos prefieren referirse a este fenómeno haciendo hincapié en su dimensión técnico-tecnológica y emplean la expresión "revolución tecnológica" (Gómez, 2000) y la consideran como paradigma para las comunicaciones. En este artículo, preferimos referirnos a este cambio como "cultura visual"1 para remarcar la dimensión cultural y estética de dichos cambios.

Es a partir de lo cultural y lo estético de este nuevo contexto que lo comunicacional se convierte en una plataforma que media la permanente reconstrucción social del mundo actual que hacen los individuos y las sociedades para encontrarle sentido. Sin embargo, Sturken \& Cartwright (2003) señalan que es precisamente lo visual lo que facilita el ejercicio y la reproducción del poder en la sociedad actual, al invisibilizar su influencia y predominio en la construcción y reconstrucción de las ideologías. Lo visual permite organizar la dimensión comunicativa de las prácticas sociales, tomando en consideración los múltiples actores sociales presentes en la esfera pública.

Por ejemplo, en relación al discurso periodístico, Saad y De la Hoz (2016) notan la necesidad de un viraje de la objetividad hacia la interpretación de los datos. Además, señalan que las prácticas tradicionalmente informativas, como el periodismo, deben ensayar una nueva narrativa "basada más en la humanización de la noticia, la personalización, la representación y por ende, la interpretación de los hechos [para dar paso a] una subjetividad ética y honesta que aporta a la estética" (p. 177). Sin embargo, el ensayo visual es poco usado como forma de comunicación en el discurso periodístico, cuando podría contribuir a la interpretación de la realidad.

El objetivo de este artículo es caracterizar al ensayo visual como producto comunicativo que, a diferencia de otros productos visuales y audiovisuales, permite la argumentación y la construcción de un pensamiento, a partir de lo visual, para contribuir a la construcción de una esfera pública inclusiva al servicio del bien común. Su hibridez es su característica

1 De acuerdo con Mirzoeff (2003), "la cultura visual no depende de las imágenes, sino de la tendencia moderna a plasmar en imágenes o visualizar la existencia” (p. 23). 
más potente ya que le permite entretejer ideas, emociones y afectos para introducir la subjetividad y al Otro. Es desde esta relación con esa Otredad que propone un conocer e interactuar con la realidad diferente, en respuesta a la estetización de la comunicación social actual, y que obtiene su veracidad desde la intersubjetividad con la que se construye.

Para esto, es necesario analizar los procesos que han contribuido a la estetización tanto de la sociedad actual como de la comunicación social, para luego caracterizar al ensayo visual como producto comunicativo articulador de lenguajes. Es a partir de este análisis que es posible reflexionar sobre las implicancias que tiene el uso del ensayo visual dentro del espacio público para la comunicación social.

\section{La estetización del mundo y de las comunicaciones}

La globalización y el desarrollo de las nuevas tecnologías introducen cambios importantes en las relaciones culturales. Proponen modalidades de interacción social que moldean las dinámicas de consumo desde lo visual. Se da un predominio de la imagen. El mundo y la comunicación se estetizan y funcionan dentro de la cultura visual.

\subsection{Globalización}

Para algunos autores, la internacionalización de la comunicación tiene como fecha de inicio 1492, con el descubrimiento de América, debido a su conexión con "el imperialismo y el colonialismo" (Sinclair, 2009, p. 11). Si bien en esa época aún no existía la imprenta, la transmisión de la información se daba mayormente a través de imágenes, como el caso de las pinturas, y un sincretismo religioso que servía para evangelizar. La transmisión del conocimiento de una cultura a otra se realizaba no solo con referencia a la evangelización, sino a todos los productos culturales.

Sinclair (2009) señala que existe una diferencia entre la internacionalización de la comunicación y la "comunicación internacional". Sostiene que esta última no empieza sino hasta el inicio de la Primera Guerra Mundial con "los estudios de propaganda, es decir, con el uso de la comunicación como un arma de guerra” (p. 11). Es a finales de la Segunda Guerra Mundial que las relaciones políticas y económicas se restablecieron, provocando un cambio que la afectó de manera global.

Para Sreberny-Mohammadi, citada por Sinclair (2009), existen tres etapas en la historia que moldearon las comunicaciones internacionales hasta llegar a la globalización: a) la modernización y comunicación para el desarrollo; b) la dependencia y c) la globalización. La primera etapa se produce al finalizar la Segunda Guerra Mundial y da pie al desarrollo incesante de los medios de comunicación. Durante la Guerra Fría, los Estados Unidos impulsaron una política de modernización en los países subdesarrollados (excluyendo a la URSS), buscando la lealtad de "nuevas naciones en Asia y África” (p. 12). Los Estados Unidos representaban un modelo de modernidad que se debía alcanzar mundialmente. 
La segunda etapa está marcada por las teorías sobre la dependencia y el subdesarrollo. El término "dependencia" nace en oposición a la modernización propuesta por los EE. UU. Se planteaba que esta modernización no implicaba un auténtico desarrollo del país, sino que se mantenía la condición de subdesarrollo dado que no solo el "país depende de otro por la tecnología, la inversión, etc., sino que las situaciones son originadas en el pasado" (Sinclair, 2009, p. 15).

La tercera etapa se extiende hasta la actualidad e incluye el fenómeno de la globalización. Sinclair (2009) propone que para entender la etapa de globalización es necesario hablar del althusserianismo que estudia "la ideología y el concepto de los medios como aparatos ideológicos del Estado" (p. 20). Para Althusser, citado por Sinclair (2009), la cultura podía pensarse como tal sin que tenga necesariamente una relación con la economía. Sin embargo, para Gutiérrez, citado por Cáceres Calderón (2006), desde un punto de vista políticoeconómico, la globalización ocasiona la materialización de la sociedad, lo que implicaría la reducción de la soberanía de los Estado-nación, la unificación y diferenciación de las tecnologías, así como la rápida integración económica de los mercados a través de formas que reorganizan la vida social y que están moldeadas por "nuevas relaciones globales que a su vez configuran una comunicación mundializada” (Cáceres Calderón, 2006, p. 16).

Por otra parte, Armand Mattelart, citado por Cáceres Calderón (2006), ve el fenómeno de la globalización como el surgimiento de la "comunicación-mundo", pero que son dos rostros de una sola realidad en camino de "descomposición y recomposición" (p. 17). De ahí que la globalización sea un fenómeno complejo, que afecta (y es afectada) por las dimensiones sociales, económicas, tecnológicas, culturales y comunicacionales.

Existe también el concepto de "glocalización" que es necesario mencionar, debido a su amplia utilización en las comunicaciones, sobre todo en la televisión y en el cine. Para Roberson, citado por Cáceres Calderón (2006), la glocalización “implica la construcción de consumidores cada vez más diferenciados y la 'invención' de 'tradiciones' de consumo, pero plantea el argumento de que lo global y lo local constituyen, no excluyen, el uno al otro" (p. 17). Un ejemplo de glocalización es la adaptación de formatos extranjeros televisivos en países a los que no estaban dirigidos en su inicio, para adherir la narrativa, las costumbres y características sociales y culturales del nuevo país al que va dirigido.

Estos cambios que se han dado, a lo largo de la historia, han afectado a las relaciones sociales, políticas, económicas, culturales y, por ende, a las comunicacionales de la humanidad. Se ha generado una combinación de culturas a través de una convivencia de todo lo que involucra a las naciones y sus identidades, es decir, se ha generado una hibridez cultural. Debido a las migraciones, se produce una desterritorialización de las culturas, generando un tráfico cultural que complejiza las nuevas culturas híbridas.

\subsection{Cambio tecnológico}

Dentro del proceso de globalización, el papel de los medios está asociado a la función de los aparatos tecnológicos como objetos, producto de la modernización, así como a su 
impacto en las audiencias. Por ejemplo, la prensa es "el primer caso masificado de acceso a la información y posibilidad de comunicación gracias a la tecnología subyacente a ella, la imprenta" (Villanueva, 2015, p. 5). Es recién a partir de la invención de la radio y la televisión que este acceso masivo a la información requiere de un instrumento de telecomunicación para enviar un mensaje. (Villanueva, 2015). Un mecanismo de telecomunicación es un medio masivo cuando tiene un alcance que cubre a un amplio grupo de personas que coinciden en espacio y tiempo. Mientras más grande sea este alcance, mejor.

Este acceso masivo y plural a la información, a través de distintos medios, ha logrado democratizar la distribución de la información, fortaleciendo las relaciones entre varias culturas. Adicionalmente, las redes sociales (Facebook, Twitter, Instagram y otras) potencializan la comunicación a través de la participación activa y personalizada de los individuos para construir comunidades virtuales de intereses compartidos. Estas nuevas formas de interacción (a través de los medios) crean un nuevo tipo de consumidor, quien ya no solo recibe e interpreta información, sino que ahora es un prosumidor: alguien capaz de negociar a través del medio masivo y crear su propio contenido. "Ver para creer y postear para existir" es una frase que representa al siglo XXI.

Este cambio (en el uso de los medios) se traduce en una modificación en la percepción de los aparatos de telecomunicación. Según Huber (2002) y su teoría antropológica del consumo, los productos, por encima de su utilidad, están llenos de connotaciones simbólicas. Es decir, que la satisfacción por la utilidad del producto pasa a un segundo plano. Para Hernani (2018),

el consumo de productos nace de una selección individual que retorna como atributos de una personalidad singular, y luego en preferencias y gustos que crean una igualdad (a partir de la diferencia) en grupos, llamados [...] neo-tribus (p. 11).

En la misma línea, Bauman, citado por Huber (2002), sostiene que "todas las percepciones y expectativas [...] están moldeadas dentro de una nueva institución fundacional: el mercado" (p. 29). Surgen nuevas formas de construir las identidades individuales y colectivas. Para Campbell, citado por Huber (2002),

los individuos no buscan tanto la satisfacción en el producto mismo como el placer de la experiencia ilusoria que construyen a partir del significado asociado (al producto). La actividad esencial del consumo, por lo tanto, no es la selección, la compra o el uso actual de los productos, sino la búsqueda imaginativa del placer para el cual se presta la imagen del producto, siendo el consumo "real" en gran parte el resultado de este hedonismo "mental" (p. 28).

Para estos nuevos consumidores, la ilusión de comprar un producto causa tanto placer como el mismo acto de comprar. La imagen del producto cobra relevancia dentro del proceso de consumo. Este deja de ser un simple acto de compra-venta y se transforma en una fuente de satisfacción personal y colectiva. Así, los bienes se convierten en signos de relaciones interpersonales y jerarquías culturales que visibilizan las relaciones 
interpersonales que actúan como "elemento constitutivo de la sociedad" por encima de las clases sociales (Huber, 2002, p. 28). Estas relaciones entre los grupos sociales marcan los gustos y preferencias de sus integrantes, funcionando como criterios de pertenencia y diferenciación. Hernani (2018) señala que estudios anteriores

hicieron un análisis de las razones que tenían los televidentes para ver programas concursos y series policiales. Estos fraccionan las categorías de gratificación en autoidentificación, base para la interacción social, diversión y educación (p. 12).

En la globalización, el cambio tecnológico se desarrolla dentro de la esfera económicofinanciera, pero también desde la esfera de la información y la comunicación. Son estos últimos los que afectan directamente las formas de conocer de los individuos, relacionando lo visual y el placer al interior de las dinámicas del consumo. La imagen se posiciona en la vida cotidiana e influye en los procesos de construcción de las identidades individuales y colectivas.

\subsection{Predominio de la imagen / lo visual}

En la sociedad de consumo, la superficialidad de la interacción de los consumidores hace que el placer de poseer el producto se concentre en la gratificación que proporciona tanto su apariencia estética como lo que esta simboliza. Este principio hedonista se define como la “estilización o estetización” del consumo (Huber, 2002, p. 30). Es la capacidad de seducción del producto lo que logra que un consumidor lo prefiera por encima de otro. Entonces, la valoración de las cosas no se da en el "mundo del valor [en sí], sino de seducirlas, es decir, de desviarlas de ese valor, y por tanto de su identidad, de su realidad, para llevarlas al juego de las apariencias" (Baudrillard, 2002, p. 29). La seducción desconcierta a la persona que ve, la hace víctima del deseo y dudar en relación a su identidad con el fin de que la elija. Por lo que la utilidad de los productos queda relegada a un segundo plano (Baudrillard, 2002).

Estamos en una cultura que exhibe sin tregua el goce y promete a todos una satisfacción perfecta e inmediata, "una sociedad hiperfestiva" que glorifica por todas partes los principios consustanciales al "estadio estético de la vida" (Kierkegaard), que se caracteriza por la búsqueda de placeres instantáneos, el gusto por experiencias efímeras y sensitivas, el descubrimiento de ambientes embriagadores (Lipovetsky \& Serroy, 2015, p. 327).

Lipovetsky \& Serroy (2015) hablan de una sociedad a la que le es necesario el placer visual que, a través de las características particulares visuales, genera un significado con valor social o cultural. Por ejemplo, ¿por qué preferir una bebida gaseosa sobre otra o una poco conocida?, ¿cuál es la diferencia entre comprar unas zapatillas estadounidenses y otras europeas? La elección que una persona hace, frente a diversas opciones, es impulsada por las expectativas que estas generan.

Víctor Vroom define Valence como la orientación afectiva anterior a respuestas particulares. Respuestas deseadas por una valoración individual considerada 
positiva y aquello que él desea evitar, lo que considera negativo: por lo tanto, las valoraciones son escaladas sobre un rango virtual (unbounded) de valores positivos y negativos (Behling \& Starke, 1973, p. 374).

La naturaleza sensible de la imagen permite traducir este "valencia" de Vroom en la conexión afectiva que el consumidor establece con el producto. Se puede decir, entonces, que esta es una época en la que las elecciones de una persona dependen del impacto que los estímulos visuales ejercen sobre ella. En este contexto, los productos visuales como la fotografía, los videos y películas adquieren mayor relevancia comunicacional. En estas primeras décadas del siglo XXI, la imagen y lo visual hacen de la comunicación un proceso interactivo en el que predomina lo simbólico.

\section{El ensayo visual como articulador de lenguajes}

El ensayo visual, por su naturaleza híbrida, permite incidir en las interacciones de los distintos tipos de lenguajes (verbal, visual, audiovisual) que se han empleado y emplean dentro de la comunicación social. En primer lugar, se hará una revisión teórica sobre la relación entre los diferentes tipos de lenguajes Luego se presentará algunas definiciones del ensayo audiovisual, resaltando sus características y su capacidad de construir nuevas interpretaciones de la realidad. Finalmente, se abordará el tema del ensayo fotográfico como una forma de pensamiento.

\subsection{Lo visual versus lo verbal, un falso dilema}

Entre los autores clásicos que han abordado la relación entre los medios y el aprendizaje en las sociedades se encuentran Marshall McLuhan, Harold Innis, Jack Goody, Erick Havelock y Walter Ong. Estos autores, sin embargo, han puesto un mayor énfasis en el estudio de la adquisición de la escritura alfabética y cómo esta generó un impacto en el aprendizaje en la cultura occidental. McLuhan quizá sea el autor pionero y con mayor intuición para reflexionar sobre las posibilidades cognoscitivas que abre la tecnología. Junto con los autores mencionados, McLuhan (1972) considera que, con la adquisición del alfabeto, las palabras perdieron su fuerza resonante que le conferían un poder mágico a las sociedades orales.

Así, a diferencia del mundo oral, en el cual el sentido más desarrollado era el oído, el modo visual (estimulado por la escritura) trajo como resultado la idea de la secuencia "antesdespués", "causa-efecto", perdiéndose la simultaneidad que se vivía en el mundo oral. McLuhan (1972) considera que las tecnologías afectan la relación entre nuestros sentidos. Es por ello que la introducción de la escritura, la imprenta y los medios electrónicos han roto la relación natural que existía entre nuestros sentidos cuando sólo teníamos comunicación oral (Núñez Murillo, 2015). En palabras de McLuhan (1972),

si se introduce una tecnología, sea desde dentro o desde fuera, en una cultura, y da nueva importancia o ascendencia a nuestros sentidos, el equilibrio o proporción 
entre todos ellos queda alterado. Ya no sentimos del mismo modo, ni continúan siendo los mismos nuestros ojos, nuestros oídos, nuestros restantes sentidos. La interacción entre nuestros sentidos es perpetua, salvo en condiciones de anestesia. Pero cuando se eleva la tensión de cualquiera de los sentidos a una alta intensidad, éste puede actuar como anestésico de otros (p. 44).

McLuhan (1972) diferenció en la historia de las comunicaciones al hombre "tipográfico" del "electrónico". El primero era el hombre formado por los medios impresos, pensaba con un orden encadenado, la lógica cerebral le conducía a la decisión conforme al pensamiento elaborado con antelación. El hombre electrónico es antisecuencial: su pensamiento se organiza mediante mosaicos de realidad, olvidándose de la técnica intercalada y se entrega al espectáculo de forma pasiva. Así como la adquisición de la escritura alfabética produjo una reestructuración en el pensamiento, la preponderancia (cada vez mayor) de las imágenes ha estimulado un pensamiento visual y una representación polisémica del mundo.

Mitchell (2009) ha teorizado el tema de la imagen y el pensamiento visual. Citando a Rorty, señala que la historia de la filosofía muestra que el pensamiento occidental estuvo enfocado inicialmente en la comprensión de las "cosas" (Edad Antigua y Medieval), luego en las "ideas" (Edad Moderna) y finalmente en el "lenguaje" o "palabras" (Edad Contemporánea). A este último enfoque, Rorty, citado por Mitchell (2009), lo llama "giro lingüístico" (p. 19). Sin embargo, en estos tiempos, estaríamos frente a otro giro conceptual, el "giro pictorial" o "visual".

Lo que da sentido al giro pictorial no es que tengamos una forma convincente de hablar de la representación visual que dicte los términos de la teoría cultural, sino que las imágenes (pictures) constituyen un punto singular de fricción y desasosiego que atraviesa transversalmente una gran variedad de campos de investigación intelectual. La imagen ha adquirido un carácter que se sitúa a mitad de camino entre lo que Thomas Kuhn llamó un "paradigma” y una "anomalía”, apareciendo como un tema de debate fundamental en las ciencias humanas, del mismo modo que ya lo hizo el lenguaje: es decir, como un modelo o figura de otras cosas (Mitchell, 2009, p. 21).

Estaríamos entonces en una época en la que la imagen predomina sobre el lenguaje verbal. No se trata de que la imagen complementa al texto, sino de que la imagen habla por sí misma y el pensamiento no sólo es verbal, sino visual. Así, García Gil (2011) resalta que los medios audiovisuales (al igual que los sonoros, visuales y escritos) condicionan la visión que se tiene del mundo, desdibujándose cada vez más las fronteras entre la ficción y realidad, lo que posibilita nuevas formas de entender y representar el mundo ${ }^{2}$. El hombre que está inmerso en un entorno audiovisual comienza a ser distinto al hombre de otras épocas, pero es difícil precisar las características psicológicas de este nuevo hombre.

2 El lenguaje audiovisual es distinto al oral y al escrito. De alguna manera, es más amplio, porque requiere la atención del oído y la visión, sin inclinarse hacia un lado de la balanza como en los otros lenguajes. Al igual que con la escritura, el lenguaje audiovisual no desplaza a la oralidad, sino que la recrea. 
Los cambios están sucediendo muy rápido, e inmersos en el proceso no es fácil sacar conclusiones. Santos (1998) explica que

si quisiéramos establecer el estereotipo del "hombre audiovisual" podríamos atribuirle unos rasgos psicológicos que son debidos a la influencia ejercida por los medios de comunicación social (p. 54).

Así, este sería un hombre "sensitivo", pues la imagen recorre un camino que llega antes a la sensibilidad para hacer luego mella en la inteligencia. En cambio, la palabra (hablada o escrita) recorre el camino inverso: primero impresiona la inteligencia y luego la sensibilidad. En nuestros días, se comprende principalmente por medio del contacto directo, por la práctica y no por representación. El hombre de sociedades orales captaba la naturaleza con toda la extensión de sus sentidos. En esta época, estaríamos volviendo a este tipo de conocimiento y expresión sensitiva, pero a través de la tecnología audiovisual.

Desde el punto de vista epistemológico, Simone (2001) hace un recuento de lo que llama "la historia del conocer". En ella identifica una "primera fase" que coincidió con el invento de la escritura; la denominada "segunda fase" comenzó veinte siglos después con el invento de la imprenta. La "tercera fase" nace con los media. Pero el autor aclara que el surgimiento de una nueva fase se debe a dos aspectos: el "técnico" y el "mental". El fenómeno técnico consiste en el hecho de que continuamente se inventan "instrumentos" vinculados con el conocimiento (el estilo y la pluma, la imprenta, la computadora). En cambio, el mental está constituido por el paso de la oralidad a la escritura y el segundo paso de la lectura a la visión y la escucha; un tránsito que también ha producido cambios en nuestro modo de pensar.

Los motores de la "tercera fase" de la historia son la televisión y la computadora, con todos los efectos que han tenido en la sociedad. El libro impreso ha dejado de ser el emblema (único y principal) del saber y de la cultura. De esta manera, se genera un nuevo orden de los sentidos, en el que la vista y el oído han intercambiado nuevamente de lugar después de siglos de primado de la visión alfabética. La enorme cantidad de estímulos auditivos y visuales (que suelen darse de manera simultánea) han hecho perder importancia a la visión alfabética y a su soporte típico: el texto escrito.

El hombre renuncia a la conquista de la visión alfabética en el momento en que, con el desmedido crecimiento de la información mediada por el oído y la visión no alfabética, ha tenido la impresión de disponer de fuentes de conocimiento igualmente ricas (Simone, 2001, p. 42).

En el escenario de la sociedad de la "tercera fase", casi todos los parámetros vigentes en la sociedad tradicional (para la creación y difusión de los conocimientos) han cambiado. El volumen de conocimientos en circulación es infinitamente mayor gracias a las computadoras. Como ya se mencionó, mientras la lectura y el empleo de códigos alfabéticos favorecen la formación y el uso de la inteligencia secuencial, el conocimiento (a través de la imagen) favorece la inteligencia simultánea que se caracteriza por la capacidad de tratar al mismo tiempo diferentes informaciones. 
No podemos decir que el rol del lenguaje visual o audiovisual frente a la oralidad o la escritura sea de desplazamiento o coexistencia separada, sino que permite la recreación de los otros lenguajes. Lo audiovisual utiliza a lo oral y lo escrito de una forma nueva, distinta, y produce (como todo sistema comunicativo) un impacto en la sociedad y la cultura que empieza a vislumbrarse y comprenderse. Lo único que podemos afirmar con certeza es que, aunque un lenguaje haya adquirido predominancia en un momento determinado, nunca reemplaza plenamente a otro (Núñez, 2015).

Sartori (1998) ha llegado a imaginar el nacimiento de un "homo videns", ya que la naturaleza del video ha impactado en el homo sapiens, producto de la cultura escrita. Sin embargo, hay que tomar con cuidado esta postura (sobre todo cuando afirma que la imagen va a destronar a la palabra), pues no se trata de que la presencia simultánea de las imágenes reemplace al lenguaje verbal (oral y escrito), sino que, como ya se dijo anteriormente, lo visual integra a lo verbal, potencializando una sensorialidad simultánea y holística.

Mirzoeff (2003) señala que lo visual no funciona solo, sino que se articula con lo verbal o lo sonoro, justamente para fijar uno de los múltiples sentidos que la polisemia de la imagen propone. En esa línea, Mitchell (2003) señala que "no vivimos en una era exclusivamente visual" (p. 23). La naturaleza híbrida del ensayo visual lo ubica como bisagras que articulan lo verbal y lo visual, aprovechando las interacciones que se dan entre ambos lenguajes. Si bien es cierto que lo verbal (especialmente lo verbal escrito) demanda una secuencialidad en el conocer, que impone cierto orden, la pregunta es ¿qué tanto aporta esta secuencialidad y orden en la sociedad de hoy?

Dicho ritmo estaba en concordancia con el surgimiento y la consolidación de la sociedad industrial y la producción en serie. Se necesitaba un orden que fuera entendido y asumido por todos, a fin de que la sociedad y la producción económica funcionasen. Paralelamente, estos cambios socioeconómicos fueron acompañados por la consolidación del método científico de Descartes, basado sólidamente en la lógica. Es justamente esta última la que brinda la capacidad de jerarquizar la secuencia que la escritura propone.

La alianza entre estos dos instrumentos vinculados al conocimiento instaura en Occidente una única visión del saber válida bajo la etiqueta de "científico". Nacen las ciencias tal como las conocemos ahora y se deja de lado más quince siglos de la era cristiana de formas de conocer. Este cambio es el que se materializa justamente en lo que históricamente se denomina la Edad Moderna. Dos guerras mundiales y el cambio de la sociedad industrial a una financiera (gracias al desarrollo tecnológico) han generado una serie de cuestionamientos a las bases que sustentan el modelo.

En este contexto, en el que se cuestionan las bases filosóficas de la modernidad y comienza una búsqueda por nuevas formas de interpretar el mundo, surgen los cambios reseñados en los apartados de este artículo y que configuran lo que se conoce como "cultura visual". Es dentro de esta que 
lo visual, a diferencia de lo textual, proporciona abundante y variada información simultáneamente, la cual se procesa a través de múltiples y diversas lecturas paralelas que implican un manejo transdisciplinar o no disciplinar de la información; así como la capacidad de moverse cognitivamente a lo largo y ancho de diferentes niveles de síntesis. Uno puede leer una imagen en segundos mientras que la lectura de un texto, por más a la ligera que se haga, demorará por lo menos el triple (Marquina, 2016, p. 91).

Dentro de la cultura visual, el desarrollo tecnológico y electrónico (que ha invadido de artefactos visuales la vida diaria) hace que proliferen esquemas personales de visión, permitiendo definir a las personas como "sujetos visuales". El ensayo visual justamente es justamente una propuesta que parte de este sentir.

\subsection{EI ensayo visual como producto que construye sentido}

Arnheim, citado por Pesci (2007), señala que todo pensamiento es de naturaleza fundamentalmente perceptual y que los procesos básicos de la visión implican mecanismos esenciales del pensamiento. De allí que la visualización no sustituye al discurso verbal, sino que lo hace más comprensible. La cultura visual constituye un campo en el que lo visual se constituye como el centro donde se crean y discuten significados. Los estudios visuales (y el ensayo visual como expresión de los mismos) hacen posible renovar los estudios sociales, comunicacionales y artísticos, produciendo nuevo conocimiento.

El ensayo visual busca superar la división existente entre el saber lógico racional y el saber que surge de la experiencia sensible. "Cualquier reflexión sobre el ensayo, entretanto, siempre pensó esa 'forma' como esencialmente 'verbal', esto es, basada en el uso del lenguaje escrito" (Machado, 2010, p. 2). Un ensayo visual es una combinación de imágenes y textos que son ensamblados como un todo, de acuerdo con cierta racionalidad y su mayor fortaleza radicaría en la sinergia que se produce entre las diferentes formas de expresión que se combinan en el ensayo visual (Pauwels, 1993), el cual genera un evento comunicativo que opera mediante asociaciones. El ensayo visual no sólo comunica una idea, sino que desencadena un proceso de pensamiento que incluye a esta, pero también a las emociones y los afectos asociados (Machado, 2010). En todo caso, ¿cuál sería la diferencia con el fotorreportaje, el video-documental o el cine documental?

Hay una diferencia central que (dejando de lado por el momento la diferencia que causan en el espectador la imagen fija y la imagen en movimiento) existe entre el reportaje o el documental y el ensayo visual: los primeros buscan informar, mientras que el ensayo busca argumentar. Si bien, en términos formales, todos estos productos comunicacionales pueden hacer uso de casi los mismos recursos lingüísticos (y hasta paralingüísticos) su objetivo comunicativo es diferente.

El ensayo no busca informar. Por lo tanto, no está necesariamente anclado a la realidad, cosa que sí sucede en el reportaje y en el documental. El ensayo visual, 
al enunciarse como tal, explicita su naturaleza subjetiva, se libera de la necesidad de verosimilitud y busca sostenerse en la coherencia y consistencia de su propuesta comunicativa. Sin embargo, comparte con aquellos, su vinculación con la veracidad. Según Roque (2017), "la veracidad es la disposición moral de acercarse a la verdad, de decirla y defenderla".

Desde la percepción sensible, lo visual incluye no solo la subjetividad, sino una perspectiva relacional, donde la validez o verdad se define en una dinámica intersubjetiva. La imagen es un espacio de negociación de subjetividades que construye sentido contrastando la intencionalidad del que la construye con la capacidad de significación del que la deconstruye (Mirzoeff, 2004). Así, el reportaje y el documental buscan informar con veracidad y considerando lo real. El ensayo busca argumentar, pudiendo convencer (o no) con veracidad y considerando la coherencia y la consistencia.

Esta distancia con lo real le da al ensayo visual mayores posibilidades creativas, potenciando su capacidad comunicativa. "Presupone una conceptualización del todo"3 (Pauwels, 1993, p. 199). Es decir, que argumenta no solo a través de lo que muestra, sino también desde dónde y cómo lo muestra, pues implica una comunicación en la que el fondo y la forma, el medio y el mensaje, se funden en beneficio de una mayor capacidad comunicativa.

El ensayo visual busca relacionar diferentes modalidades expresivas (lenguaje verbal, visual, afectos y emociones) para defender una idea, demandando a los receptores una apertura para interpretar y conectar con la subjetividad del creador del ensayo. Sin embargo, es en este proceso de emisión-recepción del ensayo visual que se genera una comunicación mucho más integral ya que la argumentación del ensayista y la interpretación del receptor son multisensoriales.

En relación con la categoría discursiva, un ensayo visual ocupa un lugar intersticial entre la objetividad (propia de un discurso científico) y la subjetividad (asociada a un discurso artístico). Sin embargo, Machado aclara que no se trata de pensar el ensayo como situado en la frontera entre la literatura y la ciencia, ya que el ensayo "es la negación misma de esa dicotomía, porque en él las pasiones invocan el saber, las emociones construyen el pensamiento y el estilo pule el concepto" (Machado, 2010, p. 2). De allí que no es posible dar una definición cerrada y estática del ensayo visual. Lo que se puede hacer es dar los lineamientos de lo que implica. Como lo señala Pauwels,

definir el ensayo visual como una combinación de material visual y verbal podría convertirse fácilmente en una categoría general. Sin embargo, prefiero limitar este concepto a las aplicaciones verbales / visuales que combinan palabras e imágenes, de tal manera que estas dos formas distintas de expresión se sumen en una forma única 
y complementaria. Por lo tanto, el uso de imágenes, como meras ilustraciones de un texto verbal, no cabría en esta definición ${ }^{4}$ (Pauwels, 1993, p. 199).

Entonces, la clave de la construcción de un buen ensayo visual estaría en la combinación precisa de imágenes y palabras, que, aunque teniendo significado propio, juntas cobren un significado novedoso. No hay reglas sobre la cantidad de palabras, ni tampoco limitaciones sobre el uso o manipulación de las imágenes. Es más, tomando en cuenta la naturaleza amplia de lo visual, con imágenes, no necesariamente se está hablando de fotografías.

Asimismo, se deben considerar los avances tecnológicos que posibilitan la creación de ensayos no solamente visuales, sino audiovisuales o multimodales. Independientemente del lenguaje usado, lo que importa es la habilidad para generar nuevas ideas, apelando no solamente a una racionalidad argumentativa, sino a lo que se podría llamar una "sensibilidad argumentativa". En relación con las múltiples posibilidades que abre el ensayo audiovisual, Pauwels (2012) dice:

El ensayo visual preferiblemente debe definirse como un enfoque, un método o una configuración que desempeña diferentes modalidades expresivas de una manera abierta / implícita ya que las nuevas tecnologías de hecho siguen empujando los límites de lo que es posible. Las imágenes en movimiento y las características no lineales de la tecnología contemporánea permiten combinaciones mucho más sofisticadas de texto, imágenes, sonido, diseño, etc., evolucionando hacia ensayos audiovisuales en lugar de ensayos puramente visuales. Se pueden concebir ensayos visuales que sean aún más multimodales o multisensoriales que vayan más allá de la "vista y el sonido"5 (p. 2).

Más allá de las definiciones (al considerar el ensayo visual como un formato válido y viable para la investigación y presentación de informes en ciencias sociales, incluyendo la comunicación) se debe tener en cuenta las expectativas específicas de esta actividad disciplinaria. Pauwels (1993) señala algunas recomendaciones generales de varios autores que dan una idea aproximada de lo que implica la producción científica de imágenes:

4 "Defining the visual essay as a combination of visual and verbal material could easily become a catch-all category. However, I prefer to limit this concept to verbal/visual applications that combine words and images in such a way that these two distinct forms of expression add to the vision or statement that is being provided, each in their unique, complementary way. So, the use of visuals as mere illustrations of a verbal statement would not fit in this definition" (texto original en inglés).

5 "The visual essay preferably needs to be defined as an approach, a method or set-up that plays out different expressive modalities in a somewhat open ended/implicit manner rather than by its specific formal qualities, as new technologies indeed keep pushing the boundaries of what is possible. Moving images and non-linear features of contemporary technology allow for far more sophisticated combinations of text, images, sound, design etc., evolving towards audiovisual essays rather than purely visual essays. Visual essays that will be even more multimodal or multisensory by going further than 'sight and sound' are conceivable, but today the dominant 'senses' that are being addressed in both new and old media (of a non-transient nature) are still vision and hearing" (texto original en inglés). 
- Requiere una preparación minuciosa: la teoría debe guiar la producción y el procesamiento de la imagen en todas sus etapas.

- Tiene implicaciones epistemológicas: sustanciar meticulosamente las decisiones de naturaleza teórica, metodológica o técnica de los informes.

- Para influencias involuntarias e incontroladas, se debe evaluar cómo y hasta qué punto estas influencias e instancias afectan lo que se considera normal $\mathrm{o}$, al menos, lo que podría considerarse aceptable en la configuración de la investigación.

- Debe esforzarse por ubicar al sujeto: la información contextual significativa debe, en la medida de lo posible, ser parte del producto visual en sí mismo.

Pesci (2007) anota que los estudios visuales buscan encontrar sus propias narrativas maestras, pues son un medio joven y amorfo investigando su propia identidad; no obstante, por su inclinación más antropológica que política a la cultura, hacen posible renovar la unificada historia del arte, produciendo un conocimiento nuevo. Las formas de generar ensayos visuales pueden ser diversas. Pesci (2007) se centra en el "video-ensayo", pero lo que afirma puede ser aplicado a otras formas visuales, incluida la fotografía.

En el film-ensayo no se establece distancia entre representación y reflexión, sino que ambas se conjugan: se reflexiona representando y se representa reflexionando. Este movimiento dialéctico, que anula el concepto de ilustración tradicionalmente adjudicado a la imagen, confiere a la forma-ensayo una extraordinaria ductilidad (p. 2).

Es esta ductilidad del pensamiento visual lo que le da su potencia y proporciona una forma holística que combina sentimiento, emoción y pensamiento en el proceso reflexivo que no separa reflexión de representación, creando nuevos sentidos en el conocimiento. En la actualidad, el ensayo visual parece florecer en varias formas: en el arte, las esferas educativas, políticas, en las plataformas de medios sociales y en los medios de comunicación. Impulsado por las nuevas tecnologías, el ensayo visual se ha convertido en un vehículo contemporáneo para expresar y visualizar todo tipo de reflexiones personales, nuevas ideas, argumentos, experiencias y observaciones.

\subsection{El ensayo fotográfico como una forma de pensamiento}

Como hemos visto, la combinación de imágenes y textos (diseñados cuidadosamente para crear una sinergia) puede considerarse la forma básica del ensayo visual. Las posibilidades de generar ensayos visuales son múltiples, dependiendo de los formatos y discursos que deseemos emplear. Este apartado se centra en el ensayo fotográfico, ya que probablemente es con la fotografía que el pensamiento visual (a través de un medio tecnológico como la cámara fotográfica) tiene una historia más larga.

El origen del ensayo visual, como una categoría más amplia, puede enraizarse parcialmente en la práctica exitosa periodística y documental del "ensayo fotográfico", en revistas 
ilustradas como Life, Look y $V u$ en los años treinta y cuarenta del siglo XX. Durante muchas décadas, estas revistas proporcionaron historias convincentes, a menudo de inspiración social, que combinaban inteligentemente fotografías con leyendas o más (Pauwels, 2012). La revista Life (desde su fundación en 1936) fue una de las promotoras más prominentes del foto-ensayo por décadas (Pauwels, 1993). Este tipo de publicaciones (aunque no tuviesen una intencionalidad argumentativa, sino quizá solo ilustrativa) demuestran la potencia de la imagen para expresar y producir pensamiento.

Este tipo de fotografías (que aparecieron en revistas ilustradas como Life) podrían considerarse, en cierto sentido, como fotografías "documentales", ya que son un reflejo visual de un evento espacio-temporal particular. Sin embargo, la mayoría de las fotografías (que comúnmente se conocen como "trabajo documental") podrían también ser llamadas "sociales" en un sentido más amplio. Pero las fronteras entre lo que diferencia una imagen documental de una social no están claras, pues habría que establecer criterios que establezcan que es lo que constituye una imagen como documento, asumiendo que hay cierta "objetividad", cuando sabemos que tal objetividad no es posible.

Así, no se puede determinar si es la intención del productor de la imagen (fotógrafo) o el objeto captado por la cámara (fotografía) lo que establece las características "documentales" o "sociales" de la imagen. Pauwels (1993) se pregunta si la naturaleza "social" de la imagen es inalienable a la propia imagen. La respuesta a esa pregunta parece ser negativa, ya que toda imagen captada estará mediada no sólo por la intención del fotógrafo, sino por la tecnología misma que capture la imagen.

Vásquez (2011) diferencia el ensayo fotográfico del reportaje fotográfico, pues considera que un reportaje se arma en base al criterio de un director periodístico y no necesariamente ha sido concebido y pensado en base a un argumento. Vásquez (2011) encuentra el ensayo fotográfico más parecido a una pieza teatral en la que cada escena (en este caso cada fotografía) tiene que guardar relación con la otra. En el ensayo fotográfico debe haber una coherencia interna. También existiría un símil entre el ensayo fotográfico y la novela ya que el ensayo fotográfico es una "narración visual larga".

El fotógrafo-ensayista, se acerca a lo representado desde su subjetividad y se relaciona con el objeto a través de la cámara que funciona como mediadora en el proceso creativo. "El ensayo fotográfico es evidencia de un compromiso del fotógrafo consigo mismo" (Vázquez, 2011 , p. 306) y al hacerlo se embarca en un proceso de pensamiento creativo en el que toma posición (argumentativa, política, ideológica) sobre aquello que desea reflexionar e investigar. Razón e intuición se entretejen en el camino creativo del ensayo fotográfico, no es un trabajo lineal y tampoco puede tener una lectura lineal.

El lenguaje visual con el que se expresa le da su carácter polisémico desde su creación hasta su recepción y la magia de la imagen radica en que conecta con el lado no racional del espectador. Por otro lado, es a través de la imagen que podemos conectar sensorialmente con el otro de una manera profunda. Como lo señala Berger (2007), "el ojo del otro se combina con nuestro ojo para dar plena credibilidad al hecho de que formamos parte del 
mundo visible" (p. 15). Se podría intercambiar en esta cita "visible" por "cognoscible". Es a través de la visión que se conoce y comprende intersubjetivamente el mundo.

Teniendo en cuenta estas consideraciones, al usar la fotografía como medio de expresión de un ensayo visual, las "imágenes no deben entenderse solamente como una fase intermedia del proceso de investigación, sino como parte integral del producto final, explorando tanto el potencial mimético como el expresivo de la imagen de la cámara y ofreciendo una oportunidad inigualable para integrar la teoría y la observación"6 (Pauwels, 1993, p. 200).

El ensayo fotográfico es subjetivo; sin embargo, en el proceso de comunicarse con el Otro (a través de la combinación de palabras, imágenes, emociones, y sensaciones) nos obligamos a reexaminar nuestras ideas preconcebidas respecto a la forma de abordar un problema o fenómeno. Así, el ensayo fotográfico definitivamente puede considerarse como una de las formas de investigación visual. Aunque, al estar aún alejado de la práctica científica social tradicional, es probable que genere controversia en el ámbito académico por algún tiempo.

\section{Implicancias para la comunicación social}

Preguntarse por las implicancias que este ensayo visual tiene para la comunicación social, demanda reflexionar sobre las oportunidades, limitaciones y desafíos que esta propuesta comunicativa (en particular el ensayo fotográfico) le propone a la comunicación desde tres perspectivas: desde la academia, la formación y la profesión.

\subsection{Desde la academia ${ }^{7}$}

A comienzos del presente siglo, la cultura visual se posiciona como contexto para la vida cotidiana (Mirzoeff, 2003; Sturken \& Cartwright, 2003; Evans \& Hall, 2004; Brea, 2005) y la comunicación social. Ello ha propiciado el surgimiento de varios textos que proponen metodologías tanto para la interpretación como para el uso de las imágenes como herramientas de investigación (Schroeder, 2003). Estas metodologías de investigación se enmarcan dentro un grupo de propuestas que, si bien ponen un énfasis en lo visual, no se limita a ello y se agrupan bajo etiquetas como Arts-based Research, Practice-based Research o Practice-led Research (McNiff, 1998; Bolt, 2004; Candy, 2006; Barrett \& Bolt, 2007; Borgdorff, 2012). ¿Qué en particular le ofrecen estas propuestas a la investigación que se realiza en comunicaciones desde la academia?

6 "Images are not considered an intermediate phase of the research process but they form an integral part of the end product, exploring both the mimetic and expressive potential of the camera-image and offering unmatched opportunity for integrating theory and observation" (texto original en inglés).

7 Entendemos por "academia" al conjunto de formas de pensar, conducir, hacer y presentar la investigación científica y la construcción del conocimiento que son generalmente aceptadas e institucionalizadas dentro de la comunicación social como campo de saber. 
Los cambios que la cultura visual introduce dentro de la sociedad han ido desdibujando las fronteras entre las disciplinas y los diferentes campos de saber, así como creando nuevas sensibilidades y formas de conocer entre los individuos (Marquina, 2011). Según Pink y Leavy, citados por Carrillo (2015), esto ha facilitado que las ciencias sociales, las humanidades y las artes (en particular las visuales) exploren puntos de encuentro que han propiciado el surgimiento de nuevas propuestas de investigación sobre la base del cruce interdisciplinario de las mismas. Para Carrillo (2015),

la investigación basada en la práctica de las artes y los medios audiovisuales surge de la necesidad de estudiar por medio de la práctica misma, artefactos que son contextualizados dentro de múltiples disciplinas (p. 222).

Así, estas metodologías de investigación salen del campo de las artes y se exploran como caminos que facilitan y apoyan el trabajo creativo en los diferentes campos del saber. Esta capacidad de apoyar el pensamiento creativo es particularmente interesante para la comunicación social. Permite posicionarse dentro de la investigación académica desde la naturaleza compleja y doble dimensión, tanto científica como artística, de su saber. Para Romeu (2016),

se trata de comprender al fenómeno comunicativo desde su dimensión más prístina porque junto con Peters (2014) pienso que el fenómeno comunicativo no es síntoma de lo social, sino más bien el resultado o consecuencia del solipsismo estructural en el que caen nuestras intenciones como seres humanos frente al otro, entre las que se encuentran por supuesto las comunicativas. A nuestro modo de ver sólo desde esta visión solipsista de la comunicación, un tanto, o más bien un mucho "anticomunicativa" (entendiendo por esto todo lo que hay que desmitificar al respecto de la comunicación), puede entenderse el fenómeno comunicativo en toda su dimensión y complejidad, aunque ello precisa de un abordaje casi herético y bastante complejo, en tanto inter y transdisciplinar (p. 23).

La investigación desde la práctica permite responder a la necesidad de pensar las comunicaciones desde una perspectiva más amplia que permita dar cuenta de su complejidad. Es en esta dirección que algunos autores exploran la propuesta. Por ejemplo (tomando en cuenta la producción de medios digitales, artes electrónicas, video y cine), Carrillo (2015) utiliza las siglas IBAPAMA para referirse a la "investigación basada en la práctica de las artes y los medios audiovisuales” y la plantea como un género metodológico (p. 221).

Desde la academia, el ensayo visual (como soporte para el pensamiento y la argumentación) se ubica dentro de este campo de nuevas propuestas metodológicas para la investigación y la construcción del conocimiento desde la comunicación social. "La visualización ofrece un método para ver lo que no se ve. Enriquece el proceso de descubrimiento científico 


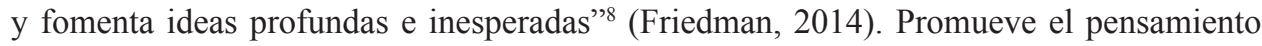
divergente sobre el fenómeno comunicativo, posibilitando encontrar nuevas perspectivas de reflexión.

En términos epistemológicos, el ensayo visual se ubica dentro del paradigma posmodernista al poner en relieve el valor de la subjetividad dentro de la construcción del conocimiento. Lo configura como un resultado siempre situado, entendible solo dentro de un tiempo y espacio específicos. Pero, además, la subjetividad lo configura también siempre negociado, como producto de mutuas concesiones y presiones, entre el ver y ser visto, dentro de una dinámica de poder. El conocimiento (tanto cotidiano como científico) se define como una construcción social. Algo que no está predeterminado, sino que es producto del encuentro de dos o más subjetividades dentro de un ecosistema comunicacional ${ }^{9}$ que lo configura y al que reconfigura simultáneamente.

El ensayo visual (como instrumento de la investigación desde la práctica) propone una forma dinámica del conocer, donde lo comunicacional y lo digital funcionan, según Amador, citado por Barrios (2015), como "proceso de co-construcción en el que los sujetos inciden en la transformación de las tecnologías y en el que éstas modifican los modos de ser, hacer y pensar de las personas" (p. 86). Ese es otro aporte. No solo permite encontrar nuevas perspectivas de reflexión, sino que ofrece una "mirada" diferente a lo ya conocido, una mirada desde el hacer, no solo desde la teoría. Justamente busca pensar haciendo. El ensayo visual busca no solo dar testimonio de una realidad (de manera holística), sino que ofrece una aproximación experiencial, interpretativa y representativa a la misma que incluye lo observable y lo no observable, lo verbalizable y lo no verbalizable, lo material y lo inmaterial, lo general y lo particular.

De allí, que no se proponga construir un conocimiento de validez universal. Ello seguramente puede incomodar a algunos. Esta es una vieja discusión dentro de la comunicación social: ¿campo de saber o disciplina? Desde este artículo, ser un campo de estudios no incomoda para nada. Por el contrario, se presenta como más coherente con esta visión actual de la construcción del conocimiento. La división en disciplinas tuvo que ver fundamentalmente con el modernismo y la creación de las universidades como las entendemos hoy. Sin embargo, la realidad no hace estas distinciones. Es en esta dirección que instrumentos como el ensayo visual podrían permitir a la comunicación social aportar de manera distintiva a la construcción y representación del conocimiento sobre la cultura y la sociedad, al estudiar la naturaleza sensorial de la experiencia y el conocimiento humanos (Pink, 2001).

8 "Visualization offers a method for seeing the unseen. It enriches the process of scientific discovery and fosters profound and unexpected insights" (texto original en inglés).

9 El ecosistema comunicacional es entendido como el "conjunto de relaciones, de acciones y de condiciones que podríamos llamar fuerzas que se interaccionan mutuamente implicando a todos en una gran fuerza comunicativa capaz de influenciar las instituciones, los destinatarios (educandos) y los agentes (educadores), así como los contenidos y las metodologías educativas" (Da Silva, 2002, p. 2). 
Desde lo metodológico, en concordancia con lo dicho, este conocimiento requiere que la subjetividad del investigador pase a ser central y completamente reconocida como parte del proceso de producción y representación del conocimiento. La imagen deja de ser tomada en reemplazo de la realidad misma. La mirada del investigador (dentro de un proceso de investigación que busca comprender un fenómeno) no es neutral. El entendimiento de lo social sólo es posible desde una perspectiva que la articule. Lo mismo sucede con la representación que de dicho fenómeno ofrece la imagen. Esta es encuadrada y compuesta desde una determinada mirada. Para Pink (2001), si bien ello obliga a estar vigilante de la subjetividad del investigador para acercarse a la dimensión no visible de la realidad, significa un avance en términos de comprender cómo se da la vida de otras personas. Sin embargo, implica mantener criterios de objetividad dentro del proceso, ya que "la realidad es subjetiva y solo se conoce como la experimentan los individuos"10 (p. 20).

No obstante, hay que tener presente que "no es únicamente la subjetividad del investigador lo que puede oscurecer su comprensión de la realidad, sino la relación entre las subjetividades del investigador y los informantes que produce una versión negociada de la realidad"11 (Pink, 2001, p. 20). En este sentido, a pesar del riesgo que la subjetividad (dentro de los procesos del conocer) pueda representar, estas metodologías ofrecen un tercer aporte a la investigación desde las comunicaciones: contribuyen a poner al descubierto otras características de las identidades de los investigadores (género, edad, nacionalidad, etc.) que pueden afectar la construcción del conocimiento desde la negociación de poder implícita en el encuentro intersubjetivo que lo construye. Ayuda a sincerar la carga de poder, desde la cual se establece la mirada del investigador hacia su objeto de estudio.

\subsection{Desde las aulas}

Desde el punto de vista de la formación de comunicadores sociales (para televisión, radio, cine, medios impresos o digitales) la cultura visual plantea la necesidad de proveer a los futuros profesionales herramientas metodológicas que posibiliten la investigación basada en la práctica de los medios de comunicación (Carrillo, 2015). El objetivo es complementar sus capacidades investigativas para comprender la naturaleza compleja y múltiple del fenómeno comunicativo actual. La visualidad hace de la comunicación social un conjunto de procesos cognitivos y expresivos más simbólicos, que demanda ser interpretados adecuadamente para comprender la realidad que comunica.

Desde la dimensión educativa, el ensayo visual ayuda al futuro comunicador social a construir esa "mirada propia" del comunicador como investigador que se acaba de

10 "Reality is subjective and is known only as it is experienced by individuals" (texto original en inglés).

11 "It is not solely the subjectivity of the researcher that may shade his or her understanding of reality, but the relationship between the subjectivities of researcher and informants that produces a negotiated version of reality" (texto original en inglés). 
mencionar en el acápite anterior. Esta perspectiva debe permitirle tanto leer como expresarse a través de imágenes. Dentro de la cultura visual, hacerlo es dotarlo con capacidades para decodificar y codificar mensajes desde lo visual y aumentar sus posibilidades para propiciar el diálogo y consenso en la esfera pública. Sin embargo, para Yezers'ka \& Zeta de Pozo (2017), la formación especializada en medios digitales casi no estaba presente en el mapa de formación de comunicadores en América Latina (2009) elaborado por la Federación Latinoamericana de Facultades de Comunicación Social (FELAFACS). En todo caso, de acuerdo con las autoras,

las universidades han asumido esa necesidad de ofrecer programas que respondan al complejo escenario de la sociedad de la información y el conocimiento, aunque con una diversidad de modelos. Ahora la preocupación es cómo formar para aprovechar mejor esas tecnologías digitales, que ya se han constituido en las herramientas connaturales a cualquier actividad periodística y comunicativa propuesta por Salaverría (2000), y pensar en la esencia del periodismo (p. 63).

Sin embargo, a pesar de las referencias frecuentes en las investigaciones sobre la existencia de la cultura visual, los programas de formación de comunicadores sociales centran su oferta de formación en aquellas materias más vinculadas a la parte operativa del funcionamiento de los equipos digitales de los nuevos medios. Se incluyen pocas materias que ayuden a desarrollar la capacidad de análisis de lo que se ve. Yezers'ka \& Zeta de Pozo (2017) explican que

desde el ámbito universitario peruano, encontramos tempranamente una preocupación por el conocimiento de los nuevos medios y su adopción en la enseñanza superior. Zeta (2001) refiere la inquietud de las universidades peruanas por la inserción de las nuevas tecnologías en los planes de estudio: cursos de computación o informática, diseño gráfico y publicitario por computadora, aplicaciones gráfico-multimedia, audio/video digital, etc., dirigidos al "saber hacer con el uso de las nuevas tecnologías" (p. 64).

La reflexión sobre la representación visual, principalmente, y sus potencialidades para expresar una determinada ideología o sistema de pensamiento queda muchas veces postergada. El empleo del ensayo visual (como estrategia de aprendizaje) ayuda a los futuros comunicadores sociales a complementar su formación, desarrollando capacidades de reflexión y crítica sobre lo que ven.

De esta manera, dada su naturaleza interpretativa, el desarrollo del ensayo visual demanda al estudiante en comunicaciones que asuma una actitud autorreflexiva que le permita identificar e integrar la relación entre las características de la representación visual, el contexto en el que se aprecia y su propia experiencia de vida como contexto en el que se construye el ensayo visual. Todo ello con el fin de dotar de sentido a lo que ve. Esta capacidad de autorreflexión es fundamental para la formación de profesionales cuyo desempeño es mayormente práctico, como es el caso del comunicador social. Su valor pedagógico (como instrumento para el aprendizaje y para la creación de conocimiento) va 
siendo reconocido dentro de los centros de formación profesional en comunicación social, a nivel universitario, en diferentes partes del mundo.

El ensayo visual es utilizado como proyecto de trabajo final de titulación en universidades de diferentes países de Norteamérica, Europa y Australia, incluso al nivel de formación de doctorado, como una forma de promover el empleo de métodos de investigación que "se enfoquen en la práctica del investigador y no únicamente en la historia o la teoría del tema" (Carrillo, 2015, p. 223) con la finalidad de incentivar su reflexión desde su propio hacer. Asimismo, esto contribuye a desarrollar una actitud y un pensamiento críticos frente a su trabajo cotidiano, potencializando sus posibilidades de agencia en los procesos de participación ciudadana desde las comunicaciones.

Es así que el ensayo visual propone realizar esta autorreflexión desde la "praxis" misma de la "experiencia estética", propiciando un conocer más vivencial a partir de la subjetividad para construir sentido, en contacto con otras subjetividades. Este no es un punto nuevo. Lo planteó Baumgarten en el siglo XVII en su obra Aesthetica, afirmando que la realidad necesita tanto de la representación lógica-científica como del lenguaje poético del pensamiento estético para poder ser aprehendida (Del Valle, 2011). Ambas formas de representación se complementan; empero, el pensamiento estético solo surge a partir de la experiencia estética, donde lo individual sensible se da desde lo individual sensible.

En este sentido, la “pragmática estética” se relaciona más cercanamente con la comunicación social como forma de percibir el mundo de una manera diferente. Parte de lo concreto, de lo que se ve. De allí que la polisemia de la imagen "introduce la incertidumbre; propiciando así, esquemas abiertos de conocimientos que se enfrentan a los esbozos cerrados de contenidos, articulados tanto en forma histórica como en disciplinas, $y$, considerados tradicionalmente como fundamentales para garantizar aprendizajes comprobables" (Marquina, 2011, p. 16).

De esta manera, la pragmática estética instaura una lógica relacional de pensamiento y de interacción con la realidad, que deja de lado los absolutos y revalora el contexto, permitiendo vincular el discurso de los contenidos con las relaciones de poder que en él se establecen y demanda el compromiso ético consigo mismo en el accionar del futuro comunicador (Marquina, 2011).

Y es que, desde la pragmática estética, la visualidad ${ }^{12}$ que desarrolla el futuro comunicador al aprender a usar el ensayo visual funciona como una táctica de negociación de subjetividades (Mirzoeff, 2004). Desde esta perspectiva, aprender a expresarse (utilizando el ensayo visual) implica posicionarse (desde la representación visual misma) dentro del proceso de negociación de subjetividades para construir un discurso que hace de la imagen "un espacio de interacción social, que permite afectar al Otro y dejarse afectar por él. Esta dinámica interactiva y social propone un camino diferente de construcción

12 Por visualidad entendemos la capacidad de asignación de significado a lo que se ve. 
del conocimiento, a través de la comprensión de la realidad" (Marquina, 2011, p. 19). Propone un trayecto que cuenta con la presencia del Otro y por lo tanto se centra más en la diferencia que en la similitud.

Es así que la reflexión sobre la construcción y la representación de la Otredad (a partir de lo estético) es otro aporte del ensayo visual a la formación profesional de los estudiantes de comunicación social. Contribuye a crear una subjetividad (que incluye al Otro desde lo cotidiano) y se convierte en la base para la toma de decisiones personales y profesionales del futuro comunicador y los juicios de valor que emite (Marquina, 2011). Ofrece un aprendizaje que contribuye a que el futuro comunicador se posicione en el mundo: primero como ser humano, con una creatividad y ética personal que guían su acción; y luego como profesional, con una visión holística de los fenómenos y una capacidad de análisis inter y transdisciplinario, que le permite desempeñarse adecuadamente dentro del espacio de construcción simbólica de la sociedad.

\subsection{Desde el desarrollo de la profesión}

La sociedad actual, dentro de la "modernidad líquida" de Bauman (2000), plantea a la comunicación social la necesidad, hoy más que ayer, de crear espacios y plataformas de interacción social que permitan la construcción de sentido que el ser humano (tanto individual como colectivamente) necesita para funcionar en el marco de la búsqueda del bien común. Para Pérez-Díaz, citado por Abril (2010), en dicho contexto,

el desarrollo de la "esfera pública" depende de un sentimiento de pertenencia a una comunidad particular y este sentimiento arraiga en experiencias compartidas que reciben su forma y su sentido de determinadas narraciones, que "preparan el terreno" a ritos que contribuyen a reforzar tales sentimientos (p. 21).

Así, cuando el cambio y la imagen son las únicas constantes, la comunicación social (mediatizada y mediada por los medios de comunicación masiva) afectan, más que nunca, los procesos de construcción de las identidades individuales y colectivas. Además, influyen también en la conformación del sentido de pertenencia y comunidad, "a través de la enunciación y representación simbólica de los sucesos que ocurren en la sociedad" (Ramírez \& Marquina, 2016, p. 17). Esta situación es más compleja en sociedades con democracias jóvenes, como las latinoamericanas, donde la multiplicidad y diversidad cultural de algunas de estas (como el caso peruano) la complejizan aún más. En estas sociedades, que requieren

potenciar los espacios de representación y participación ciudadana con carácter inclusivo, la vida cotidiana y la constitución de identidades políticas de acción colectiva, se ven fuertemente mediadas por las prácticas y discursos periodísticos que establecen los actores desde los medios de comunicación (Ramírez \& Marquina, 2016, p. 15). 
Así, los medios de comunicación de masas utilizan lo visual y lo digital para simbólicamente conectar con la identidad personal de los sujetos y afectar las prácticas sociales que posibilitan consolidar o subvertir el orden establecido. Ponen en circulación imaginarios que visualmente reflejan y conectan con las estructuras internas de las matrices culturales que funcionan en el corazón de la sociedad y establecen referentes de acción individual y colectiva (Abril, 2010). En este contexto, aún los referentes identitarios (que se ofrecen a través de la publicidad) apuntan a reforzar aquellos roles que mantienen el statu quo dentro del sistema socioeconómico. Según Ferry, citado por Rossi (2007),

de los estudios de la comunicación de masas aún en tiempos de crisis del Estado de bienestar y los modelos de servicio público del audiovisual europeo, podemos sintetizar en una ya tradicional definición de la publicidad política: una sociedad de los públicos, donde los individuos aceptan un rol genérico diseñado desde el mercado mediático, el cual es significativo referente identitario.

Dentro de la cultura visual, los medios de comunicación han contribuido sustantivamente a la creación de una esfera pública, con características espectaculares, donde los políticos son protagonistas de un espectáculo en el que la imagen está (muchas veces) por encima de la idea. Para Abril (2010),

Aunque los rituales políticos modernos siguen centrados en la palabra, la acción política contemporánea manifiesta una presencia constante de formas expresivas tomadas en préstamo de otros campos de acción social (p. 28).

Los ensayos visuales pretenden utilizar la imagen en favor de la construcción de un pensamiento que articule ideas, emociones y afectos desde lo visual. Bien dice el saber popular: una imagen vale más que mil palabras. Según Purchase, Andrienko, Jankun-Kelly \& Ward, citados por Friedman (2014), “desde cualquier punto de vista, el poder de lo visual proviene de su capacidad de capturar estructuras conceptuales más complejas que las palabras"13. El sentido se construye dentro de lo visual, articulando el fondo y la forma de la comunicación. Por ejemplo,

las noticias que se incluyen en los diarios señalan los temas a discutir y reflexionar socialmente. El orden en que las presentan, el espacio que le dan a cada una, el color con que las remarcan, etcétera, sugiere al lector la importancia que debiera dársele a cada una dentro del debate público (Ramírez \& Marquina, 2016, p. 17).

Dentro de la cultura visual, el ensayo visual tiene una doble capacidad comunicativa, cuando es usado en la esfera pública por los medios de comunicación, dado el alto grado de estetización y digitalización que estos presentan. Al articular lo visual y lo digital, permite la construcción de lo político estrechamente vinculado a la acción, potenciando

13 "From whatever viewpoint visualisation is defined, its power comes from its ability to capture more complex conceptual structures than words can" (texto original en inglés). 
la agencia de las diferentes comunidades de intereses dentro de la sociedad. La acción no nace del conocimiento simplemente, sino de la comprensión de la realidad y esta solo se alcanza al vincular los datos con nuestra propia subjetividad. En términos colectivos, la intersubjetividad (que surge de lo visual unido a lo digital) es lo que marca la diferencia. Para Karatzogianni (2012),

Es la gobernanza interna de nuestros sentimientos y emociones en relación con lo digital lo que potencialmente puede marcar una diferencia en lo político. Las emociones actúan como un reconocimiento del afecto subjetivo, formando la plataforma desde la cual se puede racionalizar y materializar el comportamiento político $^{14}$ (p. 246).

La presencia de la Internet no solo ha potencializado los campos de acción tradicionales de los medios de comunicación masivos, sino que les ha abierto nuevas posibilidades de actuación. La Internet se proyecta como el espacio para la convergencia de los mismos por su hipertextualidad (muy acorde con la sensibilidad de las audiencias de hoy) y su capacidad de comunicar a través tanto de lo audiovisual como de lo textual (Pombo, 2011). Esta polifonía y versatilidad hacen más efectiva su influencia sobre los procesos políticos, así como de construcción y reconstrucción de las identidades colectivas que orientan las prácticas políticas.

Haciendo una analogía desde el periodismo, a diferencia de los fotorreportajes o videoreportajes, el ensayo visual pasaría a cumplir el papel que desempeñan las columnas de opinión en la prensa escrita o los programas periodísticos de opinión que se transmiten por la televisión. El reto es no solo informar, sino fundamentalmente articular un pensamiento que aproveche la naturaleza híbrida del ensayo visual para hacer que el dato se transforme en significado. Para Ramírez \& Marquina (2016), el ensayo visual "como una plataforma de comunicación simbólico cultural, sobre la cual transcurre el quehacer periodístico, utiliza el potencial de la narración visual para reconstruir la realidad de forma dinámica, sensitiva y emotiva" (p. 33).

Según Tedesco, citado por Marquina (2016), el ensayo visual responde a la necesidad de que la sociedad actual "sometida a un ritmo acelerado y constante de cambio, debería dotarse de instituciones capaces de manejar la incertidumbre sin apelar a la supresión del debate" (p. 94). Desde la imagen, esta posibilidad se complementa, además, con la interacción social con lo distinto a uno que lo visual propicia, contribuyendo al autoconocimiento del individuo. Es desde esa perspectiva que la comunicación y el conocimiento se reconfiguran como prácticas de comprensión de la realidad que incluyen la dimensión ética para la toma de decisiones y se traducen en prácticas sociales que vinculan lo individual con lo colectivo de la acción (Marquina, 2016). De allí que el ensayo visual, en este contexto comunicativo,

14 "It is the internal governance of our feelings and emotions in relation to the digital that can potentially make a difference to the political. Emotions act as a recognition of subjective affect, forming the platform from which political behaviour can be rationalized and materialized" (texto original en inglés). 
ejercita el pensamiento y la percepción en la aceptación del Otro, de aquel, aquella o aquello que no se conoce. La naturaleza interpelativa de lo visual abre al sujeto hacia el Otro, creando la oportunidad para construir un imaginario colectivo que surja de la interacción social (Marquina, 2016, p. 94).

La imagen funciona como filtro (unas veces estereotipado otras no) que media nuestra relación con la realidad, pero cuya influencia (debido a su relación con la tecnología) es difícil de reconocer. Sin embargo, es sobre la base de estos filtros visuales que construimos al Otro. En términos políticos, según Abril (2010), "poseen una eficacia simbólica mucho más inmediata que el mero discurso [verbal]. Hablan, no ya a la racionalidad estratégica de electores individuales, sino a la sensibilidad y la identidad colectiva de actores sociales enraizados local y culturalmente" (p. 28). Es en esta dirección que Mitchell (2009) define a la imagen como el resultado de la negociación de subjetividades que se da a través de la interacción compleja entre visualidad, aparatos, instituciones, cuerpos y la figuración.

Desde la cultura visual, la comunicación se hace más simbólica, por lo que el conocer es un proceso que demanda el pensamiento crítico del sujeto para calar por debajo de las manifestaciones superficiales de la ideología, la personalidad y lo social (Yúdice, 2002). Así, la imagen no solo representa la construcción social de lo visual, sino que funciona simultáneamente como la construcción visual de lo social (Mitchell, 2003). En este sentido, para sociedades como la peruana, el uso del ensayo visual por la comunicación social aporta a la construcción de la ciudadanía al ofrecer imágenes de la vida cotidiana como experiencia transcultural mediada por la presencia del Otro que apunten a construir una esfera pública inclusiva orientada al debate político del bien común.

\section{Reflexiones finales}

La comunicación social actual articula (bajo la etiqueta de cultura visual) los cambios sociales, culturales, económicos, tecnológicos y epistemológicos introducidos por la globalización, las nuevas tecnologías y la dimensión estética del mundo, así como por los mismos procesos de comunicación. Si bien el ensayo visual es un producto comunicativo no tan nuevo, sus potencialidades expresivas e investigativas responden a las características que la cultura visual le imprime a la comunicación social en nuestros días.

El ensayo visual articula lo visual y lo verbal de manera complementaria e indivisible. Al permitir "conocer haciendo", posibilita descubrir nuevas perspectivas para ver la realidad que no es posible trazar de otra manera. Su naturaleza híbrida liga permanentemente la teoría con la práctica y relaciona la percepción individual con la colectiva. Así, permite a la subjetividad comunicar y construir conocimiento. Además, posibilita un imaginario personal que deviene en colectivo a través de una dinámica intersubjetiva.

En la academia, el ensayo visual (como instrumento de investigación desde la práctica) potencia la creatividad: desde el hacer, visibiliza dimensiones de la realidad que no se pueden apreciar de otra manera. En las aulas, el ensayo visual le permite al futuro 
comunicador desarrollar su capacidad autorreflexiva, esquemas de pensamiento abiertos y una perspectiva ética que guíe su accionar profesional. En el desempeño de la profesión, el ensayo visual responde a la sensibilidad del hombre actual. Dentro de la cultura visual, el ensayo visual promueve la construcción de un imaginario colectivo abierto y dinámico que centra el foco de atención en la diferencia, pero que posibilita articular la acción de la mano de la creatividad y la ética.

\section{Referencias}

Abril, G. (2010). Cultura visual y espacio público-político. Cuadernos de Información y Comunicación, 15, pp. 21-36. Recuperado de http://dialnet.unirioja.es/servlet/ ejemplar? codigo $=252834$

Avendaño, N. (2017). Las competencias investigativas en las ciencias de la comunicación: percepción de profesores universitarios. Revista Cultura de Guatemala, 38(1), 111-124. Recuperado de http://ezproxybib.pucp.edu.pe:2048/login?url=http:// search.ebscohost.com/login.aspx?direct=true \&db=a9h\&AN=124791333\&lang= es\&site $=$ eds-live $\&$ scope $=$ site

Barrios, H. (2015). Subjetividades en el ágora digital: cuestiones para la educación y la bioética. Revista Latinoamericana de Bioética, 15(2), 84-95. Recuperado de http:// eds.b.ebscohost.com.ezproxybib.pucp.edu.pe:2048/eds/pdfviewer/pdfviewe

Barrett, E. \& Bolt, B. (Eds.). (2007). Practice as research. Approaches to creativity arts inquiry. Londres: I. B. Tauris.

Baudrillard, J. (2002). Contraseñas. Barcelona: Anagrama.

Bauman, Z. (2000). La modernidad líquida. México, DF: Fondo de Cultura Económica. Recuperado de http://www.oei.org.ar/edumedia/pdfs/T14_Docu1_ Lamodernidadliquida_Bauman.pdf

Behling, O \& Starke, F (1973). The Postulates of Expectancy Theory. The Academy of Management Journal, 16(3), 373-388.

Berger, J. (2007). Modos de ver. Barcelona: Gustavo Gili.

Bolt, B. (2004). Art beyond representation. The performative power of the image. Recuperado dehttps://www.academia.edu/939327/Art_beyond_representation_ the_performative_power_of_the_image

Borgdorff, H. (2017). O conflito das faculdades: sobre teoria, prática e pesquisa em academias profissionais de artes. Opus, 23(1), 314-323. Recuperado de https:// anppom.com.br/revista/index.php/opus/article/view/420/418 
Brea, J. (2005). Los estudios visuales. Por una epistemología política de la visualidad. En J. Brea (Ed.), Estudios visuales: la epistemología de la visualidad en la era de la globalización (pp. 5-16). Madrid: Akal.

Cáceres Calderón, C. (2006). Viabilidad de una emisora de tv local, en tiempos de globalización. El caso de la ciudad de Arequipa (tesis de maestría). Pontificia Universidad Católica del Perú. Recuperado de http://tesis.pucp.edu.pe/ repositorio/bitstream/handle/123456789/78/CACERES_CALDERON_ZAIDA_ VIABILIDAD_DE_EMISORA.pdf

Candy, L. (2006). Practice Based Research: A Guide. Recuperado de https://www. creativityandcognition.com/resources/PBR\%20Guide-1.1-2006.pdf

Carrillo, P. (2015). La investigación basada en la práctica de las artes y los medios audiovisuales. Revista Mexicana de Investigación Educativa, 20(64), 219-240 Recuperado de http://ezproxybib.pucp.edu.pe:2048/login?url=http://search. ebscohost.com/login.aspx?direct=true $\& \mathrm{db}=$ eue $\& A N=1009$

Carter, P. (2007). Interest: The ethics of invention. En E. Barrett \& B. Bolt (Eds.), Practice as research. Approaches to creativity arts inquiry. Londres: I. B. Tauris.

Da Silva, G. (2002). Ecosistema educativo. Recuperado de http://www.riial.org/espacios/ educom/educom_prop1tall6.pdf

Del Valle, J. (2011). La dignidad de la imaginación. Alexander Baumgarten y el contexto del nacimiento de la estética. Areté. Revista de Filosofía. 23(2), 303-328.

Evans, J. \& Hall, S. (2004). What is visual culture? En J. Evans \& S. Hall (Eds.), Visual Culture: the reader (pp. 1-7). Londres: SAGE.

Fiske, J., Anzola, P. \& Ravassa, G. (1984). Introducción al estudio de la comunicación. Bogotá: Norma.

Friedman, A. (2014). The relationship between research method and visual display: a study of conference proceedings in the field of knowledge organization. Information Research, 19(4). Recuperado de http://eds.b.ebscohost.com.ezproxybib.pucp.edu. pe:2048/eds/detail/detail?vid=11\&sid=1ad31020-494d-480a-967b-a48ee00b6c7 e\%40sessionmgr4007\&bdata=Jmxhbmc9ZXMmc210ZT11ZHMtbG12ZSZzY29 wZT1zaXRl\#AN=100304902\&db=lih

García Gil, M. (2011). El vídeo como una herramienta de investigación. Una propuesta metodológica para la formación de profesionales en Comunicación. Revista del CES Felipe II, 13. Recuperado de http://www.cesfelipesegundo.com/revista/ articulos2011/Monica\%20Garcia.pdf 
Gómez, C. (2000). Revolución tecnológica: un nuevo paradigma para la comunicación. Signo y Pensamiento, 36(XIX), 11-18 Recuperado de http://revistas.javeriana. edu.co/index.php/signoypensamiento/article/view/2978

Hernani, V. (2018). En modo incógnito: un estudio exploratorio sobre la representación del cuerpo femenino en la pornografía en internet. Lima: Pontificia Universidad Católica del Perú.

Huber, L. (2002). Consumo, cultura e identidad en el mundo globalizado. Estudios de caso en los Andes. Lima: Instituto de Estudios Peruanos.

Lipovetsky, G. \& Serroy, J. (2015). La estetización del mundo. Barcelona: Anagrama.

Karatzogianni, A. (2012). Epilogue: The Politics of the Affective Digital. En A. Karatzogianni \& A. Kuntsman (2012), Digital Cultures and the Politics of Emotion. Feelings, Affect and Technological Change (pp. 245-249). Londres: Palgrave Macmillan.

Machado, A. (2010). El filme-ensayo. La Fuga, 11, 1-9. Recuperado de http://lafuga.cl/ el-filme-ensayo/409

Marquina, O. (2011). Los aportes al currículo desde las artes visuales, entendidas como una manifestación de la cultura visual actual (tesis de maestría). Pontificia Universidad Católica del Perú. Recuperado de http://tesis.pucp.edu.pe/repositorio/ handle/123456789/1435

Marquina, O. (2016). La cultura visual desde el campo social de la mirada. Revista Conexión, 5(5), 88-101. Recuperado de http://revistas.pucp.edu.pe/index.php/ conexion/article/download/14990/15521

McLuhan, M. (1972). La Galaxia de Gutenberg. Génesis del "homo typographicus". Madrid: Aguilar.

McNiff, S. (1998). Art-based research. Londres: Jessica Kingsley Publishers. Recuperado de https://books.google.com.pe/books?id=PwLrBQAAQBAJ\&printsec=frontcov er\&hl $=$ es\&source $=\mathrm{gbs} \_g e \_s u m m a r y \_r \& c a d=0 \# \mathrm{v}=$ onepage $\& \mathrm{q} \& \mathrm{f}=$ false

Mirzoeff, N. (2003). Introducción: ¿Qué es la cultura visual? En N. Mirzoeff (Ed.), Una introducción a la cultura visual (pp. 17-61). Barcelona: Paidós.

Mirzoeff, N. (2004). The subject of visual culture. En N. Mirzoeff (Ed.), Visual Culture Reader (pp. 3-23). Londres: Routledge Taylor \& Francis Group.

Mitchell, W. (2003). Mostrando el ver: una crítica de la cultura visual. Recuperado de http://www.estudiosvisuales.net/revista/pdf/num1/mitchell.pdf 
Mitchell, W. (2009). Teoría de la imagen. Madrid: Akal.

Núñez Murillo, G. (2015). Culturas orales y culturas escritas. Lima: PUCP.

Pauwels, L. (1993). The visual essay: Affinities and divergences between the social scientific and the social documentary modes. Visual Anthropology, 6(2), 199-210. doi: $10.1080 / 08949468.1993 .9966615$

Pauwels, L. (2012). Conceptualizing the Visual Essay as a Way of Generating and Imparting Sociological Insight: Issues, Formats and Realizations. Sociological Research Online, 17 (1). Recuperado de http://www.socresonline.org.uk/17/1/1. html

Pesci, E. (2007). Video-Ensayo, narrativa maestra del pensamiento audiovisual. Recuperado de http://fido.palermo.edu/servicios_dyc/encuentro2007/02_ auspicios_publicaciones/actas_diseno/articulos_pdf/A6036.pdf

Pink, S. (2001). Doing Visual Anthropology. Londres: Sage Publications.

Pombo, V. (2011). La globalización digitalizada. Nómadas. Revista Crítica de Ciencias Sociales y Juridicas, 31(3), 1-6. Recuperado de https://revistas.ucm.es/index.php/ NOMA/article/viewFile/36830/35651

Ramírez, M. \& Marquina, O. (2016). Comunicación y diseño en la prensa impresa. Lima: PUCP.

Roel, V. (1998). La tercera revolución industrial y la era del conocimiento. Lima: Fondo editorial UNMSM.

Romeu, V. (2018). Reflexiones profanas en torno al arte como fenómeno comunicativo. México, DF: Editorial Nómda.

Roque, A. (19 de febrero de 2017). Verdad, veracidad y verosimilitud. PULSO, Diario de San Luis. Recuperado de http://pulsoslp.com.mx/opinion/verdad-veracidadverosimilitud/

Rossi, D. (2007). Los ciudadanos interpelados por nuevos sistemas y prácticas de comunicación: actualizando la agenda de políticas democratizadoras. Recuperado de https://nanopdf.com/download/losciudadanosinterpelados_pdf

Saad, A. \& De la Hoz, J. (2016). La enseñanza del nuevo discurso periodístico en instituciones de educación superior. Encuentros, 14(2). doi: 10.15665/re.v14i2.775

Santos, M. (1998). Imagen y educación. Buenos Aires: Editorial Magisterio del Río de la Plata. 
Salvat, G. \& Serrano, V. (2011). La revolución digital y la sociedad de la información. Sevilla: Comunicación social ediciones y publicaciones. Recuperado de https:// books.google.com.pe/books?id=EqkmWOV5QbAC\&pg=PA13\&source=gbs toc_r\&cad $=3 \# \mathrm{v}=$ onepage $\& \mathrm{q} \& \mathrm{f}=$ false

Sartori, G. (1998). Homo Videns. La sociedad teledirigida. Madrid: Taurus.

Schroeder, J. (2003). Visual Methodologies and Analysis. Visual Anthropology, 16(1), 8188. doi: 10.1080/08949460309595101

Simone, R. (2001). La tercera fase. Formas de saber que estamos perdiendo. Madrid: Taurus.

Sinclair, J. (2009). Televisión. Comunicación global y regionalización. Barcelona: Gedisa.

Sturken, M. \& Cartwright, L. (2003). Practices of Looking. An Introduction to Visual Culture. Nueva York: Oxford University Press.

Toffler, A. (1980). La tercera ola. Bogotá: Plaza \& Janés. Recuperado de http:// cruceshernandezguerra.wikispaces.com/file/view/La+tercera+ola.pdf

Vásquez, A. (2011). El ensayo fotográfico, otra forma de narrar. Quórum académico, 8(16), 301-314. Recuperado de https://dialnet.unirioja.es/descarga/articulo/3865249.pdf

Villanueva, E. (2015). Medios digitales: conceptualizando la innovación tecnológica en comunicación social. Lima: PUCP.

Yezers'ka, L. \& De Pozo, R. (2017). Integración de la cultura digital en la formación de comunicadores en Perú. Comhumanitas: Revista Científica de Comunicación, 8(1), 61-80 Recuperado de http://ezproxybib.pucp.edu.pe:2048/login?url=http:// search.ebscohost.com/login.aspx?direct=true\&db=a9h\&AN=129786606\&lang= es\&site $=$ eds-live $\&$ scope $=$ site

Yúdice, G. (2002). El recurso de la cultura. Usos de la cultura en la era global. Barcelona: Gedisa. 